\title{
A Comparison of Equity Valuation Models: Empirical Evidence from a Sample of UK Companies
}

\author{
Ja Ryong Kim \\ Dr. University of Nottingham, UK \\ B07, Si Yuan Building, University of Nottingham, Jubilee Campus, Wollaton Road, NG8 1BB, UK
}

\begin{abstract}
This paper aims to answer one main question: can the superior models in accounting field be superior in finance field? That is, can models that generate a better approximation to stock price also generate higher returns in the future? To answer this question, I conduct pricing errors analysis and time-series returns analysis. The most important finding is models that approximate stock price better tend to produce higher returns in the future; implying findings in accounting literature have practical implications to analysts and investors. The consistent rankings of models are observed throughout the research: forward earnings multiples perform the best, followed by fundamental valuation models and historical earnings multiples, and book value and sales multiples worst. However, multiples are ranked rather as a group in the UK. Interestingly, residual income models produce similar returns to forward earnings multiples, but the accuracy of their estimates varies depending on their terminal value assumptions.
\end{abstract}

Keywords: comparison, equity, valuation, models, empirical, evidence, sample, UK companies

\section{Introduction}

Estimating the intrinsic value of stocks is one of the most intriguing and important questions in accounting and finance. Many valuation models have been developed to measure the intrinsic price of stocks assuming the stock price will eventually converge to its fundamental value. However, some argue that this effort is pointless because current market price is already the intrinsic price, reflecting all valuable information (Fama (1970) and Firth (1976)). One thing they all share in common is that the intrinsic value equals the sum of present values of all future payoffs to stockholders, although methodologies and assumptions they employ are not agreed upon.

In accounting literature, it is common to adopt the efficient market hypothesis $(\mathrm{EMH})$ as the starting point, and assume model estimations to be equal to market prices. To measure the usefulness of models, academics compare the model estimation with the market price and observe how close they are: the closer they are, the better the model it is considered. Although not everyone agrees, more and more research reveals that fundamental valuation models, especially residual income model (RIM), produce a closer approximation to the market price than simple price multiples.

In contrast, most of researchers and practitioners in finance believe the market price is biased and will converge to the intrinsic value eventually in the future. They regard a better model as the one that generates more returns to investors in the future, rather than the one that better approximates the market price. Contrary to accounting researchers, analysts and fund managers believe fundamental valuation models are too sensitive to the assumptions they employ. As a result, survey results reveal that practitioners prefer simple price multiples such as price-to-earnings ratio $(P / E)$ or dividend yield $(D / Y)$ to fundamental valuation models because they are easier to use and communicate to their clients.

This paper aims to answer one main question: can the superior models in accounting research field be superior in finance field? That is, can models that generate a better approximation to stock price also generate higher returns in the future if they are used? To answer this question, I conduct two different analyses - pricing errors analysis and time-series returns analysis - and compare the performance of models in both analyses. 
This paper uses a sample of UK firms and compares the results with those for US firms. This is because not many studies have been carried out in the UK compared to the US, where a lot of researches are performed.

For the models selection, I mainly refer to Liu et al. (2002) because: (1) Liu et al. cover most of the valuation models widely used in practice or studied in academic papers under the same methodology. This fact is important because most other papers cover only a subset of models with a different methodology, making direct comparison between them hard; (2) different types of models are tested such as accruals, cash flows, forward-looking information and fundamental valuation models, providing a panoramic view about the performances of various models; (3) instead of comparing models in terms of their explanatory power (i.e., $R^{2}$ ) to the stock price, they use pricing errors to evaluate the performance of models. The pricing errors measured in the first stage analysis are used later in the second stage time-series returns analysis in this paper; and (4) Liu et al. compare performances of models in different industries, providing detailed insights to model users in different areas.

To enable the direct comparison between UK and US results, this paper tries to use the same methods that Liu et al. (2002) use. However, I release some criteria to maintain a certain number of samples, given the limited data availability compared to the US. Besides that, this paper makes other differences from Liu et al. (2002). In the first stage, pricing errors analysis, I did not use the intercept adjusted method. This is because this method produces similar results to those of the no-intercept adjusted method, but in a much difficult way. Considering the perspectives of model users who prefer simple and easy to use method, I only use the no-intercept adjusted method. Instead, this paper employs a regression methodology that is broadly used in practice and academics. In the second stage, time-series returns analysis, I depart from the EMH assumption and measure the annual and cumulative returns of models for up to five years' time horizon (i.e., from $T+1$ to $T+5$ ). Buy-and-hold returns - buying top quintile (undervalued) stocks and short-selling bottom quintile (overvalued) stocks - based on the pricing errors are used to measure the time-series returns. The first stage analysis aims to evaluate the superiority of models in terms of pricing errors that accounting researchers regard as important, and the second stage analysis focuses on the performance of models in terms of returns generation ability that financial practitioners consider important. If the rankings of models between the two analyses are similar, I can conclude that the findings in accounting literature have useful as well as practical implications to model users in finance.

This paper finds a number of interesting results that are useful to both accounting and finance researchers: (1) in the pricing errors analysis, the rankings of models between the UK and the US are almost identical: Forward earnings multiples outperform historical earnings multiples, followed by book value multiples, and sales multiples in descending order. However, two distinctive patterns are observed in the UK. Firstly, models are ranked as a group rather than as an individual model, and the differences of pricing errors for multiples within the group are minimal. Secondly, one of the residual income model (RIM) is consistently included in the first group in performance with forward earnings multiples, in contrast to the results in the US where all RIMs underperform forward earnings multiples; (2) despite its popular usage in practice, a regression methodology generates larger pricing errors than those of the harmonic mean methodology; (3) similar to Liu et al. (2002), the rankings of models are generally consistent across sectors. However, they are again ranked as a group rather than an individual model; and (4) most importantly, the rankings of models in the pricing errors analysis and the timeseries returns analysis are generally identical indicating the findings in accounting literature have useful implications to financial practitioners. Additionally, two interesting results are found from the time-series returns analysis. First, other RIMs, once excluded from the first performance group in the pricing errors analysis, are now included in the group. This implies, on average, RIMs perform similar to forward earnings multiples in terms of returns generation, but the accuracy of their estimations varies depending on the terminal value assumptions they employ. Second, buy-and-hold returns, especially short-selling returns, are largely affected by a relatively few extreme values.

\section{Methodology}

\section{Value Drivers}

The types of models and methodologies are primarily determined based on Liu et al. (2002) for the direct comparison between UK and US results. However, some models are deleted because of data unavailability in the UK, and some are added, reflecting their popularity in practice. To measure multiples, two simple and popular methods - the harmonic mean method and a regression method - are adopted considering model users' perspectives. 
Models are broadly grouped into three categories: price multiples using historical data, price multiples using forecasted data, and fundamental valuation model multiples. For the price multiples using historical data, four value drivers are chosen: book value of equity (BV), actual earnings per share from I/B/E/S (IACT), earnings before interest, taxes, depreciation and amortization (EBITDA), and sales.

Fundamental valuation model multiples include four RIMs and three DDMs with different assumptions. RIM is theoretically the same as DDM given clean surplus accounting ${ }^{1}$. However, RIM is developed to overcome the disadvantages of DDM that (1) dividends are the indicator of value distribution, not value creation, and (2) a large number of companies, especially growth companies, do not actually pay dividends making DDM inappropriate.

DDM explains equity value is the sum of the present values of expected dividends:

$$
\text { Equity Value }=\frac{D I V_{1}}{(1+r)}+\frac{D I V_{2}}{(1+r)^{2}}+\frac{D I V_{3}}{(1+r)^{3}} \ldots
$$

where $D I V_{t}$ is forecasted dividend for year $t$ and $r$ is the cost of equity. According to clean surplus accounting, dividend can be expressed as:

$$
D I V_{t}=E A_{t}+B V_{t-1}-B V_{t}
$$

where $E A_{t}$ means earnings and $B V_{t}$ means book value for year $t$.

Substituting (2) into (1),

$$
\begin{aligned}
& \text { Equity Value }=\frac{E A_{1}+B V_{0}-B V_{1}}{(1+r)}+\frac{E A_{2}+B V_{1}-B V_{2}}{(1+r)^{2}} \ldots \\
= & \frac{E A_{1}-r B V_{0}+(1+r) B V_{0}-B V_{1}}{(1+r)}+\frac{E A_{2}-r B V_{1}+(1+r) B V_{1}-B V_{2}}{(1+r)^{2}} \ldots \\
= & B V_{0}+\frac{E A_{1}-r B V_{0}}{(1+r)}+\frac{E A_{2}-r B V_{1}}{(1+r)^{2}}+\frac{E A_{3}-r B V_{2}}{(1+r)^{3}} \ldots
\end{aligned}
$$

Equation (3) is RIM estimating stock value as the current book value of equity plus the sum of the present values of abnormal earnings. Gode and Ohlson (2006) argue that the usefulness of RIM varies across sectors depending on how close firm's book value approximates its market value; therefore, RIM is expected to perform well in finance sector where financial instruments are marked to market, whereas it is not in technology sector where intangible assets - off-balance sheet item - account for a large part of market value. This argument will be verified in the sector rankings analysis later in this paper.

Three popular methods for the terminal value calculation are employed in the paper. The first model (P1) forecasts future earnings over the next five years and then assumes abnormal earnings to be maintained constant afterwards:

$$
P 1_{t}=B V_{t}+\sum_{\tau=1}^{5}\left[\frac{E_{t}\left(E A_{t+\tau}-r_{t} B V_{t+\tau-1}\right)}{\left(1+r_{t}\right)^{\tau}}\right]+\frac{E_{t}\left(E A_{t+5}-r_{t} B V_{t+4}\right)}{r_{t}\left(1+r_{t}\right)^{5}}
$$

The second model (P2) covers a five-year forecast horizon similar to $\mathrm{P} 1$, but assumes abnormal earnings will be eliminated after the horizon:

$$
P 2_{t}=B V_{t}+\sum_{\tau=1}^{5}\left[\frac{E_{t}\left(E A_{t+\tau}-r_{t} B V_{t+\tau-1}\right)}{\left(1+r_{t}\right)^{\tau}}\right]
$$

\footnotetext{
${ }^{1}$ All changes in equity are reflected in income statement. Exceptions are transactions such as dividends, repurchases or offerings. Thus, year-end book value of equity is the beginning book value of equity plus earnings minus dividends:

$$
B V_{t}=B V_{t-1}+E A_{t}-D I V_{t}
$$

where $B V_{t}$ is book value, $E A_{t}$ is earnings, and $D I V_{t}$ means dividend for year $t$.
} 
The third model (P3) covers two-year forecast horizon and then presumes firm's return on equity (ROE) will linearly converge to its sector median ROE in the next nine years, followed by the constant abnormal earnings at that level:

$$
\begin{aligned}
P 3_{t}=B V_{t}+\sum_{\tau=1}^{2} & {\left[\frac{E_{t}\left(E A_{t+\tau}-r_{t} B V_{t+\tau-1}\right)}{\left(1+r_{t}\right)^{\tau}}\right]+\sum_{\tau=3}^{11}\left[\frac{\left\{E_{t}\left(R O E_{t+\tau}\right)-r_{t}\right\} B V_{t+\tau-1}}{\left(1+r_{t}\right)^{\tau}}\right] } \\
+ & \frac{\left\{E_{t}\left(R O E_{t+12}\right)-r_{t}\right\} B V_{t+11}}{r_{t}\left(1+r_{t}\right)^{11}}
\end{aligned}
$$

This pattern is proved by the empirical evidences for European firms over time that firm's ROE converges to the median ROE in the next ten years (Palepu et al. (2007)). P1, P2 and P3 are also mentioned in Liu et al. (2002), whereas the next models are not. The fourth model (P4) is basically same as P3 but assumes firm's ROE to be linearly converge to the sector median ROE in the next five years:

$$
\begin{aligned}
P 4_{t}=B V_{t}+\sum_{\tau=1}^{2} & {\left[\frac{E_{t}\left(E A_{t+\tau}-r_{t} B V_{t+\tau-1}\right)}{\left(1+r_{t}\right)^{\tau}}\right]+\sum_{\tau=3}^{7}\left[\frac{\left\{E_{t}\left(R O E_{t+\tau}\right)-r_{t}\right\} B V_{t+\tau-1}}{\left(1+r_{t}\right)^{\tau}}\right] } \\
+ & \frac{\left\{E_{t}\left(R O E_{t+8}\right)-r_{t}\right\} B V_{t+7}}{r_{t}\left(1+r_{t}\right)^{7}}
\end{aligned}
$$

The pattern of P4 is based on the empirical findings in Nissim and Penman (2001) that earnings measures (e.g., residual earnings, residual operating income, return on common equity, and return on net operating assets) have a tendency to converge to their median value over the next five years.

Three different DDMs are additionally examined in this paper to compare the performances with those of RIMs. Despite their theoretical equivalence, DDM and RIM use different value drivers with different characteristics, so they normally produce inconsistent estimates. The first two DDMs use similar assumptions to P1 and P2 to make direct comparisons between them.

The first DDM (D1) includes a five-year forecast horizon and presumes constant dividend payouts after the horizon:

$$
D 1_{t}=\sum_{\tau=1}^{5}\left[\frac{E_{t}\left(D I V_{\tau}\right)}{\left(1+r_{t}\right)^{\tau}}\right]+\frac{E_{t}\left(D I V_{t+5}\right)}{r_{t}\left(1+r_{t}\right)^{5}}
$$

The second DDM (D2) only uses five years' dividend forecasts with no terminal value:

$$
D 2_{t}=\sum_{\tau=1}^{5}\left[\frac{E_{t}\left(D I V_{\tau}\right)}{\left(1+r_{t}\right)^{\tau}}\right]
$$

However, the third model (D3) reflects the unique characteristic of dividends that dividend payoffs are unlikely to decrease, but likely to increase when constant dividend payout ratio is assumed. The survey results in Brav et al. (2004) indicate financial executives are reluctant to change the current dividend payout ratio because increase in dividend payout ratio can be a burden in the future when the firm's performance deteriorates, while decrease in dividend payouts can cause investors' dissatisfaction. Therefore, D3 uses 3.5\% constant long-term growth rate in dividends considering historical UK GDP growth rates. Therefore, D3 is expressed as:

$$
D 3_{t}=\sum_{\tau=1}^{5}\left[\frac{E_{t}\left(D I V_{\tau}\right)}{\left(1+r_{t}\right)^{\tau}}\right]+\frac{E_{t}\left(D I V_{t+5}\right)(1+0.035)}{\left(r_{t}-0.035\right)\left(1+r_{t}\right)^{5}}
$$

Pricing Errors Analysis

By definition, the multiple is the price of a single unit of firm's performance. For example, $\mathrm{P} / \mathrm{BV}$ is the price of a single unit of book values. Therefore, if the volume of firm's performance and its multiple are known, the price of a firm can be estimated by multiplying them. However, because the multiple of a firm is hard to estimate directly, an indirect method that uses the multiple of comparable firms is widely used in practice. This indirect methodology is based on the fundamental economic 
principle: the law of one price. It states every identical product should have one same price, or arbitrageurs will buy the product in the cheaper market and sell it at the higher price in the different market, eliminating the price difference. The same rule applies to equity valuation: companies with same features should have one identical price. Specifically, if the multiple of a comparable firm is known, it can be used for that of a target firm. This can be expressed as:

$$
\text { Equity Value }\left(p_{i}\right)=\beta x_{i}+\varepsilon_{i}
$$

where $\beta$ is the multiple of a comparable firm, $x_{i}$ is the value driver of a firm and $\varepsilon_{i}$ means the error for firm $i$.

To select comparable firms to estimate $\beta$, three methods are normally used in practice: (1) analysts often choose a small number of, but most similar, comparable firms for each individual case (Goedhart (2005)); (2) firms in the same sector are chosen as comparable firms. This method is most widely used in academic research to estimate the generalised $\beta$; and (3) entire firms across sectors are selected as comparable firms. Because the first method is not suitable for the research that aims to draw a generalised conclusion, I employ methods (2) and (3) that are widely used in academic research.

In addition to the selection of comparable firms, there are also a number of measures to calculate $\beta$. Baker and Ruback (1999) use four different measurements (i.e., simple mean, harmonic mean, value-weighted mean and simple median), and find the harmonic mean and the simple median produce the smallest errors. However, considering the simple median measure produces the wider dispersion of errors than the harmonic mean does, the harmonic mean measure is considered most reliable. Kim and Ritter (1999) employ a regression measure to estimate $\beta$ for their IPO valuations. Although all measures are commonly used in practice, I chose the harmonic mean, the median and a regression measure. The harmonic mean and the median are chosen because they produce more accurate estimates than the other measures. Moreover, they are mainly used in Liu et al. (2002). A regression method is selected because its performances are yet examined in other research. By using the three different measures, this paper expects to check which measure produces the most accurate estimates in the UK.

\section{Harmonic Mean and Simple Median Measures}

In the first stage analysis, pricing errors are measured to evaluate the performance of multiples. However, the errors calculated in equation (11) can mislead the conclusion because those errors are measured in value terms, not in percentage terms. In value terms, bigger companies tend to have larger errors than those for smaller companies, making the direct comparison between multiples hard. To estimate the errors in percentage terms, equation (11) are divided by $p_{i}$ in both sides:

$$
1=\beta \frac{x_{i}}{p_{i}}+\frac{\varepsilon_{i}}{p_{i}}
$$

where $\varepsilon_{i} / p_{i}$ is the pricing error in percentage terms. For the direct comparison with Liu et al. (2002), this paper assumes that expected pricing errors to be zero,

$$
E\left(\frac{\varepsilon_{i}}{p_{i}}\right)=1-E\left(\beta \frac{x_{i}}{p_{i}}\right)=0
$$

then the multiple $\beta$ is expressed as the inverse of expected $x_{i} / p_{i}$ :

$$
\beta=\frac{1}{E\left(\frac{x_{i}}{p_{i}}\right)}
$$

As explained earlier, $\beta$ is measured using the harmonic mean of $p_{i} x_{i}$ and the inverse of the median of $x_{i} / p_{i}$. After estimating $\beta$, pricing error is measured as the gap between the market price and the model estimation divided by the market price:

$$
\frac{\varepsilon_{i}}{p_{i}}=\frac{p_{i}-\hat{\beta} x_{i}}{p_{i}}
$$

To evaluate the performances of multiples, this paper primarily uses the interquartile range of pricing errors consistent with Liu et al. (2002). 
This paper employs the ordinary least squares (OLS) regression to estimate the linear relationship between the market prices and the value drivers of comparable firms. The OLS regression does not require expected pricing errors to be zero, but it principally calculates a coefficient (i.e., multiple $\beta$ ) that minimises the sum of squared errors. The pricing errors are calculated in the same way as equation (14) to allow direct comparisons between the performances of multiples.

\section{Time-Series Returns Analysis}

Time-series returns analysis is a typical methodology used in finance to measure the performance of models or strategies over the time horizon. It estimates the returns that the model would generate if the model strategy were used in the past. A quintile based buy-and-hold strategy is employed to measure the returns consistent with Frankel and Lee (1998): buying top quintile (undervalued) stocks and short-selling bottom quintile (overvalued) stocks based on the pricing errors calculated in the first stage analysis. Both cumulative and annual buy-and-hold returns are estimated across up to five-years' time windows (from $T+1$ to $T+5$ ) based on the findings in Nissim and Penman (2001) that most earnings advantages disappear within the upcoming five years.

\section{Data}

Three data sources are used to conduct the research: (1) Compustat Global for accounting information; (2) I/B/E/S for share price, actual EPS, forecasted EPS, and sector classification; and (3) Datastream for 10-year Gilt yields and FTSE 100 index. In contrast to US data where all companies are identified by CUSIP (Committee on Uniform Security Identification Procedures) across different data sources, UK data need an additional effort to match the companies in Compustat Global and I/B/E/S. This is because Compustat Global uses ISIN (International Securities Identifying Number) and SEDOL (Stock Exchange Daily Official List) while I/B/E/S uses CUSIP as a company identification code. To match ISIN (or SEDOL) with CUSIP, the unique six digits consistently observed across the codes are compared (according to the characteristics of the codes). Specifically, the last six digits in CUSIP are the same as the first six digits in SEDOL, and the same as the middle six digits (from $5^{\text {th }}$ to $10^{\text {th }}$ ) in ISIN. To ensure the code matching is conducted in a right way, company names (not only current but also historical names) are additionally matched for each case. Finally, 2,531 companies are confirmed as being listed in both Compustat Global and I/B/E/S. The research covers from 1988 to 2008, the full time period available from both Compustat Global and I/B/E/S, to make a general interpretation for UK companies.

\section{Results}

\section{Descriptive Statistics}

Table II describes the mean, median, standard deviation and nine different percentile values for the multiples. Due to the relative size difference between value drivers, direct comparison between the multiples is not very meaningful. However, interestingly, when the results are compared to those in Liu et al. (2002), the size of values for multiples are very similar to those in the US implying comparable assumptions and methodologies are employed. Additionally, when the mean and the median are compared within the multiple, the mean is always higher than the median indicating all multiples are skewed to the right. This is probably due to the bounds in multiples: value drivers can go up without limit allowing extremely positive multiples, but cannot go down below zero restricting multiples to stay above zero.

The correlations between multiples are described in Table III. The two interesting findings are: (1) by drawing a vertical line between SALES/TP and EPS1/P, different patterns are clearly observed on each side: the correlations on the left side are considerably low (i.e., mostly smaller than 0.5 ), whereas those on the right side are significantly high (i.e., mostly larger than 0.5). This implies historical and forecasted data do not share common information to a large extent. More interestingly, multiples using forecasted data, especially earnings forecasts, are highly correlated with each other, but those using historical data are not particularly correlated even between themselves; and (2) models using future dividends (i.e., $D^{*} / P$ and three DDMs) are rarely correlated with any multiples using historical data indicating dividend payout forecasts are less relevant to the firm's historical performances.

\section{Pricing Errors Analysis}

\section{Harmonic Mean and Simple Median Measures}

Table IV displays the main result of the pricing errors analysis. The table consists of three panels according to the methodologies used in multiple calculations: the 
Table II

\section{Descriptions of the Multiples}

The mean, median, standard deviation and nine percentile values are displayed for the multiples. Horizontal lines are drawn to categorise price multiples with same characteristics: multiples using historical data, multiples using forecasted data and fundamental valuation model multiples.

\begin{tabular}{|c|c|c|c|c|c|c|c|c|c|c|c|c|}
\hline & \multirow{2}{*}{ Mean } & \multirow{2}{*}{ Median } & \multirow{2}{*}{ SD } & \multicolumn{9}{|c|}{ Percentile } \\
\hline & & & & $1 \%$ & $5 \%$ & $10 \%$ & $25 \%$ & $50 \%$ & $75 \%$ & $90 \%$ & $95 \%$ & $99 \%$ \\
\hline BV/P & 0.626 & 0.496 & 0.540 & 0.043 & 0.115 & 0.173 & 0.301 & 0.496 & 0.798 & 1.193 & 1.520 & 2.404 \\
\hline IACT/P & 0.080 & 0.070 & 0.075 & 0.007 & 0.021 & 0.032 & 0.049 & 0.070 & 0.099 & 0.136 & 0.168 & 0.252 \\
\hline EBITDA/P & 0.186 & 0.156 & 0.150 & 0.022 & 0.054 & 0.074 & 0.109 & 0.156 & 0.223 & 0.314 & 0.396 & 0.669 \\
\hline SALES/P & 1.984 & 1.301 & 2.332 & 0.134 & 0.289 & 0.399 & 0.698 & 1.301 & 2.332 & 4.156 & 6.061 & 11.826 \\
\hline EBITDA/TP & 0.137 & 0.126 & 0.077 & 0.019 & 0.047 & 0.066 & 0.092 & 0.126 & 0.168 & 0.217 & 0.257 & 0.385 \\
\hline SALES/TP & 1.450 & 1.049 & 1.444 & 0.120 & 0.241 & 0.332 & 0.576 & 1.049 & 1.771 & 2.896 & 4.128 & 7.385 \\
\hline EPS1/P & 0.085 & 0.075 & 0.045 & 0.015 & 0.030 & 0.041 & 0.056 & 0.075 & 0.103 & 0.140 & 0.170 & 0.246 \\
\hline EPS2/P & 0.099 & 0.087 & 0.051 & 0.022 & 0.040 & 0.050 & 0.066 & 0.087 & 0.119 & 0.161 & 0.196 & 0.284 \\
\hline EG1/P & 0.109 & 0.096 & 0.056 & 0.024 & 0.044 & 0.055 & 0.073 & 0.096 & 0.132 & 0.178 & 0.217 & 0.314 \\
\hline$E G 2 / P$ & 0.010 & 0.009 & 0.006 & 0.002 & 0.003 & 0.004 & 0.006 & 0.009 & 0.013 & 0.018 & 0.022 & 0.034 \\
\hline $\mathrm{ES} 1 / \mathrm{P}$ & 0.551 & 0.484 & 0.285 & 0.131 & 0.231 & 0.284 & 0.367 & 0.484 & 0.661 & 0.897 & 1.094 & 1.601 \\
\hline $\mathrm{ES} 2 / \mathrm{P}$ & 0.463 & 0.404 & 0.243 & 0.112 & 0.196 & 0.238 & 0.306 & 0.404 & 0.556 & 0.759 & 0.925 & 1.363 \\
\hline$D^{*} / P$ & 0.026 & 0.023 & 0.020 & 0.002 & 0.005 & 0.007 & 0.011 & 0.023 & 0.036 & 0.051 & 0.063 & 0.093 \\
\hline $\mathrm{P} 1 / \mathrm{P}$ & 2.128 & 1.777 & 1.358 & 0.484 & 0.806 & 0.961 & 1.267 & 1.778 & 2.574 & 3.711 & 4.610 & 7.204 \\
\hline $\mathrm{P} 2 / \mathrm{P}$ & 0.910 & 0.776 & 0.555 & 0.196 & 0.320 & 0.400 & 0.553 & 0.776 & 1.120 & 1.570 & 1.913 & 2.844 \\
\hline P3/P & 3.212 & 2.609 & 2.371 & 0.611 & 0.907 & 1.116 & 1.671 & 2.609 & 3.989 & 6.009 & 7.527 & 11.888 \\
\hline $\mathrm{P} 4 / \mathrm{P}$ & 2.559 & 2.093 & 1.854 & 0.475 & 0.731 & 0.912 & 1.341 & 2.093 & 3.195 & 4.735 & 5.960 & 9.490 \\
\hline $\mathrm{D} 1 / \mathrm{P}$ & 0.740 & 0.596 & 0.625 & 0.081 & 0.140 & 0.181 & 0.303 & 0.596 & 0.970 & 1.456 & 1.883 & 3.051 \\
\hline $\mathrm{D} 2 / \mathrm{P}$ & 0.142 & 0.125 & 0.104 & 0.017 & 0.030 & 0.038 & 0.063 & 0.125 & 0.190 & 0.267 & 0.338 & 0.516 \\
\hline $\mathrm{D} 3 / \mathrm{P}$ & 2.820 & 1.435 & 5.109 & 0.179 & 0.299 & 0.390 & 0.681 & 1.435 & 3.197 & 5.459 & 8.078 & 27.997 \\
\hline
\end{tabular}

Table III

Correlations between Multiples

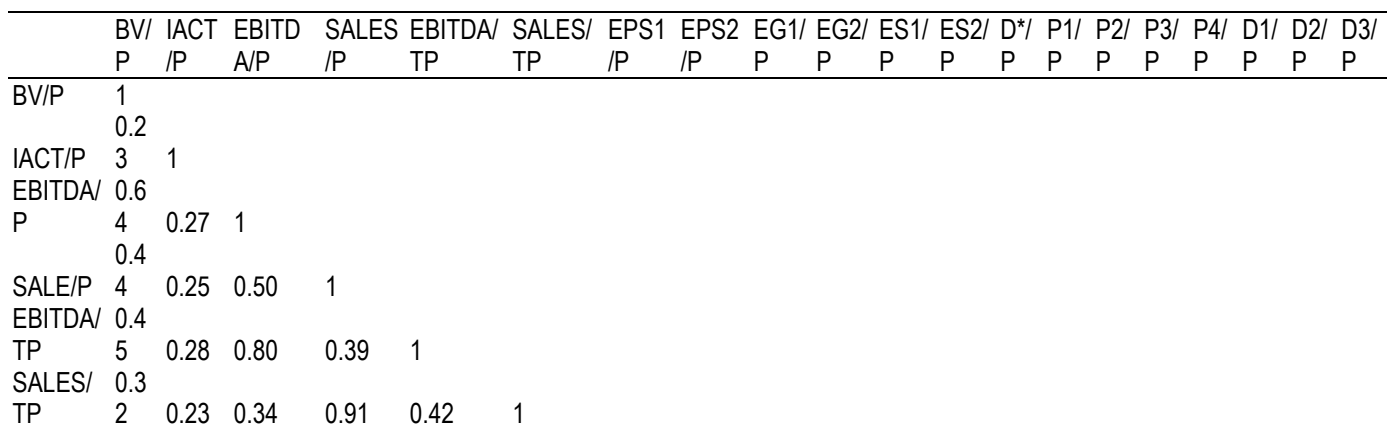




\begin{tabular}{|c|c|c|c|c|c|c|c|c|c|c|c|c|c|c|c|c|c|c|c|}
\hline \multirow[b]{2}{*}{ EPS1/P } & & \multirow[b]{2}{*}{0.46} & \multirow[b]{2}{*}{0.45} & \multirow[b]{2}{*}{0.48} & \multirow[b]{2}{*}{0.41} & \multirow[b]{2}{*}{1} & & & & & & & & & & & & \\
\hline & $\begin{array}{l}9 \\
0.4\end{array}$ & 0.56 & & & & & & & & & & & & & & & & & \\
\hline EPS2/P & $\begin{array}{l}2 \\
0.4\end{array}$ & 0.52 & 0.46 & 0.49 & 0.46 & 0.44 & 0.95 & 1 & & & & & & & & & & & \\
\hline EG1/P & $\begin{array}{l}1 \\
0.3\end{array}$ & 0.52 & 0.46 & 0.49 & 0.46 & 0.44 & 0.95 & 1.00 & 1 & & & & & & & & & & \\
\hline$E G 2 / P$ & $\begin{array}{l}2 \\
0.4\end{array}$ & 0.44 & 0.37 & 0.41 & 0.40 & 0.38 & 0.80 & 0.84 & 0.87 & 1 & & & & & & & & & \\
\hline $\mathrm{ES} 1 / \mathrm{P}$ & $\begin{array}{l}1 \\
0.4\end{array}$ & 0.51 & 0.45 & 0.49 & 0.44 & 0.43 & 0.93 & 0.98 & 0.98 & 0.85 & 1 & & & & & & & & \\
\hline $\mathrm{ES} 2 / \mathrm{P}$ & $\begin{array}{l}1 \\
0.2\end{array}$ & 0.51 & 0.45 & 0.49 & 0.44 & 0.43 & 0.93 & 0.98 & 0.98 & 0.83 & 1.00 & 1 & & & & & & & \\
\hline$D^{*} / P$ & $\begin{array}{l}8 \\
0.3\end{array}$ & 0.34 & 0.30 & 0.36 & 0.31 & 0.33 & 0.64 & 0.59 & 0.58 & 0.41 & 0.57 & 0.58 & $\begin{array}{l}1 \\
0.5\end{array}$ & & & & & & \\
\hline $\mathrm{P} 1 / \mathrm{P}$ & $\begin{array}{l}7 \\
0.9\end{array}$ & 0.43 & 0.38 & 0.42 & 0.36 & 0.37 & 0.78 & 0.84 & 0.84 & 0.68 & 0.90 & 0.92 & $\begin{array}{l}6 \\
0.4\end{array}$ & $\begin{array}{l}1 \\
0.6\end{array}$ & & & & & \\
\hline $\mathrm{P} 2 / \mathrm{P}$ & $\begin{array}{l}2 \\
0.6\end{array}$ & 0.39 & 0.67 & 0.53 & 0.52 & 0.41 & 0.68 & 0.72 & 0.71 & 0.57 & 0.72 & 0.73 & $\begin{array}{l}7 \\
0.3\end{array}$ & $\begin{array}{l}8 \\
0.7\end{array}$ & $\begin{array}{l}1 \\
0.7\end{array}$ & & & & \\
\hline P3/P & $\begin{array}{l}0 \\
0.8\end{array}$ & 0.50 & 0.51 & 0.42 & 0.43 & 0.34 & 0.71 & 0.73 & 0.74 & 0.68 & 0.75 & 0.77 & $\begin{array}{l}4 \\
0.3\end{array}$ & $\begin{array}{l}8 \\
0.7\end{array}$ & $\begin{array}{l}8 \\
0.9\end{array}$ & $\begin{array}{l}1 \\
0.9\end{array}$ & & & \\
\hline $\mathrm{P} 4 / \mathrm{P}$ & $\begin{array}{l}1 \\
0.2\end{array}$ & 0.38 & 0.60 & 0.46 & 0.47 & 0.36 & 0.66 & 0.68 & 0.68 & 0.55 & 0.68 & 0.71 & $\begin{array}{l}9 \\
0.8\end{array}$ & $\begin{array}{l}2 \\
0.7\end{array}$ & $\begin{array}{l}2 \\
0.5\end{array}$ & $\begin{array}{l}2 \\
0.4\end{array}$ & $\begin{array}{l}1 \\
0.4\end{array}$ & & \\
\hline $\mathrm{D} 1 / \mathrm{P}$ & $\begin{array}{l}9 \\
0.3\end{array}$ & 0.30 & 0.28 & 0.36 & 0.26 & 0.32 & 0.55 & 0.58 & 0.57 & 0.39 & 0.61 & 0.63 & $\begin{array}{l}7 \\
0.9\end{array}$ & $\begin{array}{l}6 \\
0.6\end{array}$ & $\begin{array}{l}1 \\
0.5\end{array}$ & $\begin{array}{l}5 \\
0.3\end{array}$ & $\begin{array}{l}7 \\
0.4\end{array}$ & $\begin{array}{l}1 \\
0.9\end{array}$ & \\
\hline $\mathrm{D} 2 / \mathrm{P}$ & $\begin{array}{l}0 \\
0.1\end{array}$ & 0.33 & 0.30 & 0.39 & 0.29 & 0.35 & 0.61 & 0.62 & 0.61 & 0.44 & 0.62 & 0.63 & $\begin{array}{l}7 \\
0.4\end{array}$ & $\begin{array}{l}6 \\
0.5\end{array}$ & $\begin{array}{l}1 \\
0.2\end{array}$ & $\begin{array}{l}9 \\
0.3\end{array}$ & $\begin{array}{l}3 \\
0.3\end{array}$ & $\begin{array}{l}5 \\
0.6\end{array}$ & $\begin{array}{l}1 \\
0.4\end{array}$ \\
\hline$D 3 / P$ & 5 & 0.17 & 0.14 & 0.17 & 0.11 & 0.14 & 0.29 & 0.29 & 0.28 & 0.13 & 0.31 & 0.34 & 5 & 2 & 8 & 6 & 6 & 1 & 9 \\
\hline
\end{tabular}

harmonic mean of firms from the same sector; the harmonic mean of firms from the cross-sectional sample; and the median of firms from the same sector. Each panel contains mean, median, and the five indicators of pricing errors dispersion: standard deviation; interquartile range; 90 percentile less 10 percentile; 95 percentile less 5 percentile; and 99 percentile less 1 percentile. This paper uses interquartile range as the main indicator of the performances of multiples as Liu et al. (2002) do.

The pricing errors of multiples using the harmonic mean of firms from the same sector are described in Panel A of Table IV. As the method implies, the means of pricing errors for all multiples are zero except those for multiples using TP. Generally, rankings and results are consistent across the UK and the US: forward earnings multiples perform the best, followed by fundamental valuation models, placing the multiples using historical data at the end. However, interestingly, multiples are ranked rather as a group than as an individual multiple in the UK. This is graphically described in Figure 1. EPS2, EG1, EG2, ES1, ES2 and P1 multiples perform the best forming the first group, followed by IACT, EBITDA and D1 multiples, and BV and SALES multiples at the end. The differences between the performances of multiples within the first group are almost negligible. The fact that the P1 multiple is included in the first group is surprising because it is the only fundamental valuation model in the group and its performances in the US are considerably worse than those of other forward earnings multiples. However, UK evidence shows that the P1 multiple consistently performs similar to other multiples in the first group across the research, implying P1 has a considerable amount of useful information about the stock price.

Figure 1 describes the distribution of pricing errors for some representative models. As explained above, three different groups are clearly distinguished: Forward earnings multiples including P1 place at the top, followed by IACT, EBITDA and DDM multiples in the middle, and BV and SALES multiples at the bottom. The more peaked distribution the multiple has around the zero pricing error line, the more accurate it is. Horizontal axis represents errors in every $10 \%$ scaled by price and vertical axis represents the percentage of observations. It is apparent that less 
Table IV

\section{Pricing Errors for Multiples using Harmonic Mean and Simple Median}

Comparable firms are based on either the same sector or the entire cross-section. Price estimations are measured as: $p_{i}=\beta x_{i}+\varepsilon_{i}$, multiples are measured as: $\beta=1 / E\left(\frac{x_{i}}{p_{i}}\right)$, the harmonic mean is used in Panel $\mathrm{A}$ and $\mathrm{B}$, and the simple median is used in Panel $\mathrm{C}$, and pricing error is $\frac{\varepsilon_{i}}{p_{i}}=\frac{p_{i}-\widehat{\beta} x_{i}}{p_{i}}$.

Panel A: Multiples using Harmonic Mean of Firms from the Same Sector

\begin{tabular}{|c|c|c|c|c|c|c|c|}
\hline & \multirow{2}{*}{ Mean } & \multirow{2}{*}{ Median } & \multirow{2}{*}{ SD } & \multicolumn{4}{|l|}{ Ranges } \\
\hline & & & & $25 \%-75 \%$ & $10 \%-90 \%$ & $5 \%-95 \%$ & $1 \%-99 \%$ \\
\hline BV/P & 0.000 & 0.177 & 0.785 & 0.768 & 1.564 & 2.127 & 3.446 \\
\hline IACT/P & 0.000 & 0.087 & 0.732 & 0.545 & 1.173 & 1.630 & 2.801 \\
\hline EBITDA/P & 0.000 & 0.125 & 0.695 & 0.564 & 1.188 & 1.672 & 3.185 \\
\hline SALES/P & 0.000 & 0.293 & 1.008 & 0.830 & 1.806 & 2.716 & 4.940 \\
\hline EBITDA/TP & -0.291 & -0.111 & 0.955 & 0.719 & 1.558 & 2.204 & 4.139 \\
\hline SALES/TP & -0.285 & 0.099 & 1.320 & 1.072 & 2.331 & 3.475 & 6.447 \\
\hline EPS1/P & 0.000 & 0.074 & 0.465 & 0.487 & 1.028 & 1.448 & 2.412 \\
\hline EPS2/P & 0.000 & 0.083 & 0.456 & 0.458 & 0.986 & 1.400 & 2.380 \\
\hline EG1/P & 0.000 & 0.083 & 0.456 & 0.458 & 0.986 & 1.400 & 2.380 \\
\hline EG2/P & 0.000 & 0.083 & 0.456 & 0.458 & 0.986 & 1.400 & 2.380 \\
\hline ES1/P & 0.000 & 0.085 & 0.458 & 0.456 & 0.982 & 1.384 & 2.366 \\
\hline ES2/P & 0.000 & 0.086 & 0.456 & 0.455 & 0.981 & 1.385 & 2.351 \\
\hline$D^{*} / P$ & 0.000 & 0.069 & 0.567 & 0.631 & 1.306 & 1.758 & 2.733 \\
\hline $\mathrm{P} 1 / \mathrm{P}$ & 0.000 & 0.089 & 0.482 & 0.457 & 0.993 & 1.408 & 2.447 \\
\hline $\mathrm{P} 2 / \mathrm{P}$ & 0.000 & 0.109 & 0.541 & 0.560 & 1.151 & 1.551 & 2.547 \\
\hline P3/P & 0.000 & 0.111 & 0.533 & 0.520 & 1.084 & 1.509 & 2.519 \\
\hline $\mathrm{P} 4 / \mathrm{P}$ & 0.000 & 0.123 & 0.581 & 0.595 & 1.212 & 1.637 & 2.669 \\
\hline $\mathrm{D} 1 / \mathrm{P}$ & 0.000 & 0.081 & 0.572 & 0.593 & 1.258 & 1.716 & 2.855 \\
\hline $\mathrm{D} 2 / \mathrm{P}$ & 0.000 & 0.076 & 0.545 & 0.586 & 1.249 & 1.693 & 2.692 \\
\hline D3/P & 0.000 & 0.083 & 0.578 & 0.594 & 1.260 & 1.718 & 2.865 \\
\hline
\end{tabular}

Panel B: Multiples using Harmonic Mean of Firms from the Entire Cross-Section

\begin{tabular}{llllllll}
\hline & \multirow{2}{*}{ Mean } & \multirow{2}{*}{ Median } & SD & \multicolumn{2}{l}{ Ranges } \\
\cline { 6 - 8 } & & & & $25 \%-75 \%$ & $10 \%-90 \%$ & $5 \%-95 \%$ & $1 \%-99 \%$ \\
\hline BV/P & 0.000 & 0.186 & 0.849 & 0.778 & 1.606 & 2.191 & 3.627 \\
IACT/P & 0.000 & 0.090 & 0.777 & 0.570 & 1.212 & 1.673 & 2.854 \\
EBITDA/P & 0.000 & 0.141 & 0.785 & 0.593 & 1.240 & 1.748 & 3.295 \\
SALES/P & 0.000 & 0.335 & 1.143 & 0.826 & 1.863 & 2.860 & 5.857 \\
EBITDA/TP & -0.332 & -0.134 & 1.060 & 0.786 & 1.656 & 2.339 & 4.369 \\
SALES/TP & -0.342 & 0.110 & 1.544 & 1.093 & 2.513 & 3.856 & 7.773 \\
\hline EPS1/P & 0.000 & 0.075 & 0.480 & 0.509 & 1.087 & 1.494 & 2.490 \\
EPS2/P & 0.000 & 0.086 & 0.470 & 0.478 & 1.033 & 1.440 & 2.432 \\
EG1/P & 0.000 & 0.087 & 0.469 & 0.479 & 1.029 & 1.438 & 2.435 \\
EG2/P & 0.000 & 0.097 & 0.500 & 0.504 & 1.087 & 1.532 & 2.554 \\
ES1/P & 0.000 & 0.089 & 0.472 & 0.477 & 1.027 & 1.435 & 2.435
\end{tabular}




\begin{tabular}{llllllll} 
ES2/P & 0.000 & 0.089 & 0.471 & 0.477 & 1.026 & 1.436 & 2.432 \\
$\mathrm{D}^{*} / \mathrm{P}$ & 0.000 & 0.064 & 0.572 & 0.691 & 1.389 & 1.805 & 2.719 \\
\hline $\mathrm{P} 1 / \mathrm{P}$ & 0.000 & 0.096 & 0.503 & 0.480 & 1.035 & 1.454 & 2.532 \\
$\mathrm{P} 2 / \mathrm{P}$ & 0.000 & 0.111 & 0.567 & 0.588 & 1.196 & 1.608 & 2.637 \\
$\mathrm{P} 3 / \mathrm{P}$ & 0.000 & 0.127 & 0.585 & 0.557 & 1.172 & 1.615 & 2.733 \\
$\mathrm{P} 4 / \mathrm{P}$ & 0.000 & 0.131 & 0.609 & 0.609 & 1.281 & 1.728 & 2.808 \\
$\mathrm{D} 1 / \mathrm{P}$ & 0.000 & 0.073 & 0.590 & 0.638 & 1.319 & 1.743 & 2.793 \\
$\mathrm{D} 2 / \mathrm{P}$ & 0.000 & 0.064 & 0.554 & 0.641 & 1.308 & 1.739 & 2.679 \\
$\mathrm{D} 3 / \mathrm{P}$ & 0.000 & 0.076 & 0.598 & 0.638 & 1.323 & 1.752 & 2.823 \\
\hline
\end{tabular}

accurate multiples (e.g., BV/P and SALES/P) have a less steep curve and more observations in the extremes compared to $\mathrm{P} 1, \mathrm{EPS} 2$ and ES2.

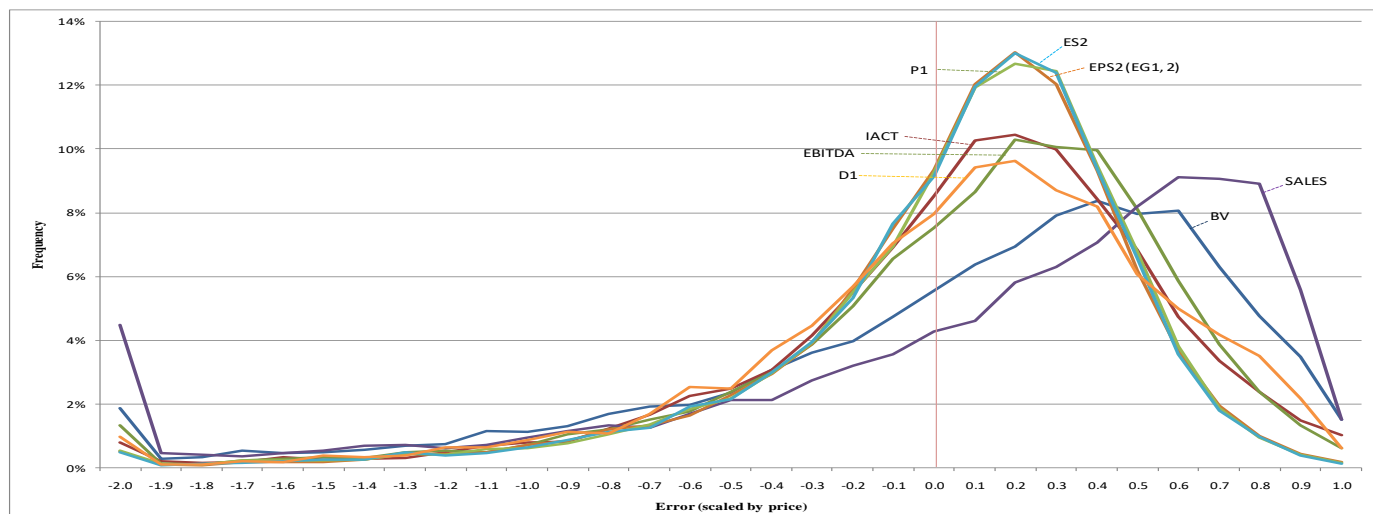

Figure 1. Distribution of pricing errors. The graph demonstrates the distribution of pricing errors for representative multiples. Multiples are estimated using the harmonic mean of firms from the same sector, and pricing errors are pooled across years. The multiples are as described in Table II. The more peaked distribution the multiple has around the zero vertical line, the more accurate it is. Horizontal axis represents pricing errors in every $10 \%$ scaled by price, and vertical axis represents the percentage of observations.

Among multiples using historical data, earnings multiples perform the best, followed by book value multiple, and sales multiple in descending order, consistent with Liu et al. (2002). Between earnings multiples, IACT/P that eliminate one-time transitory components outperforms EBITDA/P. Multiples based on enterprise value (i.e., EBITDA/TP and SALES/TP) perform worse than those based on equity value, although enterprise value is theoretically more appropriate for those value drivers.

Panel B of Table IV demonstrates the pricing errors for multiples using the harmonic mean of entire firms. Generally, errors are larger than those reported in Panel A. This is consistent with Alford (1992) and Bhojraj and Lee (2002) that comparable firms selected from the same sector contain better information than those from the cross-section. However, the rankings and patterns are still consistent with those in Panel A, similar to in the US. To be sure, the performances of EPS2, EG1 and EG2 are no longer same because cross-sectional sample is used for the comparable firms in Panel B: EPS2 and EG1 outperform EG2, and the differences between EPS2 and EG1 are negligible. P1 still places in the first group with EPS2, $\mathrm{EG} 1, \mathrm{ES} 1$ and $\mathrm{ES} 2$.

Figure 2 demonstrates the trend of interquartile ranges for multiples over time based on the results in Panel $\mathrm{A}$. Consistent with the patterns in Figure 1, multiples are classified into three groups in general and their rankings are surprisingly consistent across the time even though their absolute values fluctuate. Two interesting findings are: (1) the performances of dividend models (i.e., $D^{*} / P$ and DDMs) deteriorate significantly over time: They are considered as one of the most accurate models before 1992, but become one of the least precise models in late 2000s. Surprisingly, this period coincides 
with the changes in preferences for D/Y among financial analysts (Block (1999), Demirakos et al. (2004) and Imam et al. (2008)). Block (1999) explains the decreasing popularity of $D / Y$ is due to its decreasing accuracy in estimation when the market is growing rapidly; and (2) when the market is overheated, the accuracy of valuation models decrease sharply. Specifically, the interquartile ranges increase significantly across multiples just before the dot.com boom in 2000 , followed by a sharp drop when the boom ended. This pattern is consistent with the findings in Trueman et al. (2000) that traditional valuation models do not work appropriately during the market bubble period.

\section{A Regression Measure}

This paper employs a regression methodology whose performances are rarely tested in accounting literature despite its popular usage in practice. The results for multiples using a regression measure are reported in Table V: the overall rankings and patterns are consistent with those reported in Table IV, although there are some differences between them.

Comparing the interquartile ranges in Panel $\mathrm{A}$ and $\mathrm{B}$ of Table $\mathrm{V}, \mathrm{I}$ discover some different trends from those observed in Table IV. The interquartile ranges of multiples based on the same sector firms are not always smaller than those of multiples based on the entire firms. This is evident especially for the multiples using historical values. In addition, SALES/P outperforms BV/P in Panel B, and EBITDA/P outperforms IACT/P. Despite these conflicting facts with those observed

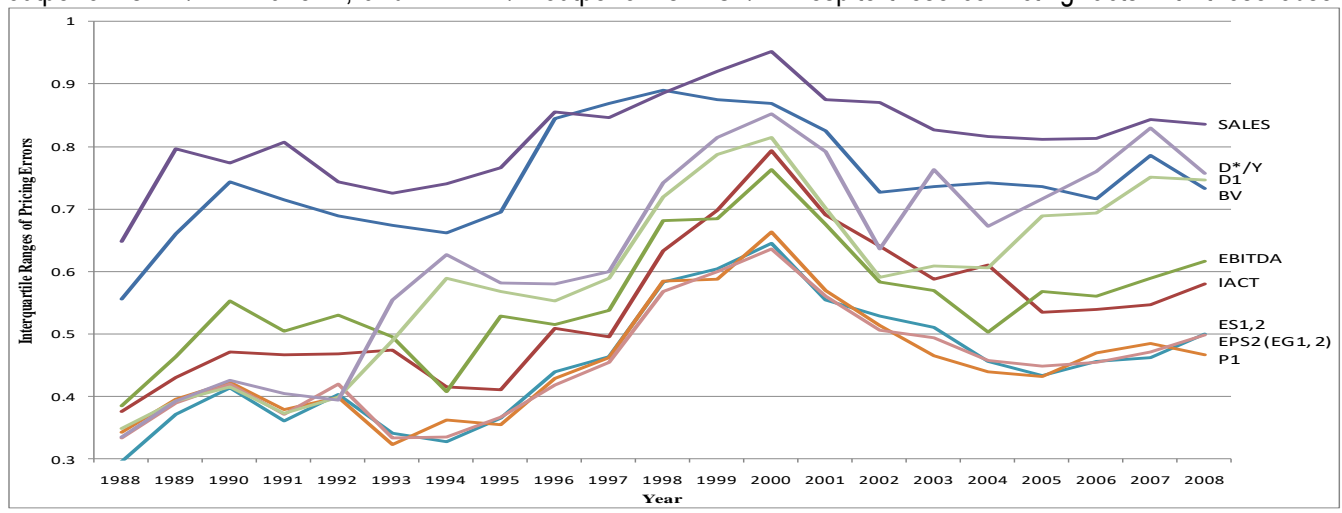

Figure 2. Interquartile ranges across time. Table V

\section{Pricing Errors for Multiples using a Regression}

The ordinary least squares (OLS) regression is used to estimate multiples. Comparable firms are based on either the same sector or the entire cross-section. Price estimations are measured as: $p_{i}=\beta x_{i}+\varepsilon_{i}$, and pricing error is $\frac{\varepsilon_{i}}{p_{i}}=\frac{p_{i}-\widehat{\beta} x_{i}}{p_{i}}$.

\begin{tabular}{llllllll}
\hline \multicolumn{7}{l}{ Panel A: Multiples using Regression based on Firms from the Same Sector } \\
\hline & \multirow{2}{*}{ Mean } & Median & SD & \multicolumn{1}{l}{ Ranges } & & \\
\cline { 5 - 8 } & & & & $25 \%-75 \%$ & $10 \%-90 \%$ & $5 \%-95 \%$ & $1 \%-99 \%$ \\
\hline BV/P & 0.094 & 0.266 & 0.744 & 0.694 & 1.460 & 2.022 & 3.258 \\
IACT/P & 0.040 & 0.126 & 0.591 & 0.572 & 1.202 & 1.686 & 2.814 \\
EBITDA/P & 0.061 & 0.184 & 0.666 & 0.563 & 1.182 & 1.670 & 3.166 \\
SALES/P & 0.169 & 0.420 & 0.863 & 0.717 & 1.532 & 2.242 & 4.207 \\
EBITDA/TP & 0.061 & 0.184 & 0.666 & 0.563 & 1.182 & 1.670 & 3.166 \\
SALES/TP & 0.169 & 0.420 & 0.863 & 0.717 & 1.532 & 2.242 & 4.207 \\
\hline EPS1/P & -0.025 & 0.059 & 0.501 & 0.526 & 1.105 & 1.519 & 2.584 \\
EPS2/P & -0.075 & 0.028 & 0.519 & 0.517 & 1.094 & 1.582 & 2.704 \\
EG1/P & -0.075 & 0.028 & 0.519 & 0.517 & 1.094 & 1.582 & 2.704 \\
EG2/P & -0.075 & 0.028 & 0.519 & 0.517 & 1.094 & 1.582 & 2.704 \\
ES1/P & -0.080 & 0.027 & 0.525 & 0.510 & 1.109 & 1.587 & 2.730 \\
ES2/P & -0.079 & 0.026 & 0.523 & 0.509 & 1.106 & 1.574 & 2.709 \\
D*/P & 0.064 & 0.122 & 0.534 & 0.609 & 1.272 & 1.700 & 2.556 \\
\hline P1/P & -0.084 & 0.028 & 0.550 & 0.514 & 1.124 & 1.621 & 2.927 \\
& & & & & & &
\end{tabular}




\begin{tabular}{|c|c|c|c|c|c|c|c|}
\hline $\mathrm{P} 2 / \mathrm{P}$ & -0.050 & 0.079 & 0.604 & 0.611 & 1.240 & 1.712 & 2.849 \\
\hline $\mathrm{P} 3 / \mathrm{P}$ & -0.064 & 0.072 & 0.611 & 0.579 & 1.199 & 1.700 & 2.904 \\
\hline $\mathrm{P} 4 / \mathrm{P}$ & -0.031 & 0.112 & 0.638 & 0.629 & 1.288 & 1.783 & 2.923 \\
\hline $\mathrm{D} 1 / \mathrm{P}$ & 0.009 & 0.080 & 0.572 & 0.604 & 1.307 & 1.772 & 2.888 \\
\hline $\mathrm{D} 2 / \mathrm{P}$ & 0.019 & 0.081 & 0.545 & 0.589 & 1.276 & 1.715 & 2.666 \\
\hline D3/P & 0.008 & 0.080 & 0.577 & 0.606 & 1.312 & 1.776 & 2.918 \\
\hline \multicolumn{8}{|c|}{ Panel B: Multiples using Regression based on Firms from the Entire Cross-Section } \\
\hline & \multirow{2}{*}{ Mean } & \multirow{2}{*}{ Median } & \multirow{2}{*}{ SD } & \multicolumn{4}{|c|}{ Ranges } \\
\hline & & & & $25 \%-75 \%$ & $10 \%-90 \%$ & $5 \%-95 \%$ & $1 \%-99 \%$ \\
\hline BV/P & 0.142 & 0.317 & 0.731 & 0.680 & 1.404 & 1.914 & 3.236 \\
\hline IACT/P & 0.096 & 0.186 & 0.634 & 0.543 & 1.157 & 1.578 & 2.702 \\
\hline EBITDA/P & 0.138 & 0.264 & 0.675 & 0.537 & 1.108 & 1.569 & 2.989 \\
\hline SALES/P & 0.224 & 0.490 & 0.904 & 0.633 & 1.459 & 2.232 & 4.585 \\
\hline EBITDA/TP & 0.138 & 0.264 & 0.675 & 0.537 & 1.108 & 1.569 & 2.989 \\
\hline SALES/TP & 0.224 & 0.490 & 0.904 & 0.633 & 1.459 & 2.232 & 4.585 \\
\hline EPS1/P & -0.002 & 0.089 & 0.501 & 0.521 & 1.122 & 1.556 & 2.605 \\
\hline EPS2/P & -0.062 & 0.048 & 0.522 & 0.524 & 1.127 & 1.604 & 2.729 \\
\hline EG1/P & -0.063 & 0.048 & 0.522 & 0.524 & 1.124 & 1.598 & 2.736 \\
\hline EG2/P & -0.044 & 0.074 & 0.544 & 0.542 & 1.167 & 1.640 & 2.809 \\
\hline ES1/P & -0.064 & 0.049 & 0.524 & 0.517 & 1.125 & 1.580 & 2.683 \\
\hline $\mathrm{ES} 2 / \mathrm{P}$ & -0.064 & 0.049 & 0.522 & 0.517 & 1.120 & 1.580 & 2.680 \\
\hline $\mathrm{D} / \mathrm{P}$ & 0.080 & 0.136 & 0.532 & 0.624 & 1.286 & 1.689 & 2.574 \\
\hline $\mathrm{P} 1 / \mathrm{P}$ & -0.019 & 0.078 & 0.554 & 0.525 & 1.178 & 1.665 & 2.754 \\
\hline $\mathrm{P} 2 / \mathrm{P}$ & -0.030 & 0.102 & 0.601 & 0.623 & 1.262 & 1.708 & 2.836 \\
\hline $\mathrm{P} 3 / \mathrm{P}$ & -0.020 & 0.122 & 0.618 & 0.582 & 1.222 & 1.680 & 2.896 \\
\hline $\mathrm{P} 4 / \mathrm{P}$ & 0.005 & 0.150 & 0.622 & 0.619 & 1.281 & 1.746 & 2.874 \\
\hline $\mathrm{D} 1 / \mathrm{P}$ & 0.072 & 0.132 & 0.576 & 0.645 & 1.323 & 1.749 & 2.789 \\
\hline $\mathrm{D} 2 / \mathrm{P}$ & 0.035 & 0.096 & 0.544 & 0.609 & 1.279 & 1.718 & 2.654 \\
\hline $\mathrm{D} 3 / \mathrm{P}$ & 0.075 & 0.136 & 0.583 & 0.650 & 1.337 & 1.758 & 2.824 \\
\hline
\end{tabular}

in Table IV, I still believe these adverse patterns are not significant because the standard deviations of them still follow the consistent trend for most multiples.

Another interesting result from Table $V$ is the rankings of RIMs are different between Panel $A$ and $B$. Panel $A$ displays the same ranking as that observed in Table IV: P1 performs the best, followed by P3, P2, and P4 in decreasing order. However, the ranking in Panel $\mathrm{B}$ is $\mathrm{P} 1, \mathrm{P} 3, \mathrm{P} 4$, and $\mathrm{P} 2$ in descending order, changing the position between P4 and P2. These conflicting rankings show that the appropriateness of terminal values is dependent on circumstances such as methodologies or underlying assumptions, confirming the inference I drew previously.

Overall, multiples using a regression have larger pricing errors than those for multiples using the harmonic mean. Therefore, results in Panel A of Table IV, that have smallest pricing errors, are used for the sector rankings analysis and the timeseries returns analysis.

\section{Time-Series Returns Analysis}

The second stage analysis employs 9,518 firm-years and covers 892 British firms from 1988 to 2007 . Year 2008 prices are not used because I/B/E/S provides prices only up to March of 2008 , which are not suitable to estimate year-end based annual returns. To measure the time-series returns for up to forthcoming five years (i.e., from $T+1$ to $T+5$ ), year 2003 to 2007 are not used as the target years.

The summary of buy-and-hold returns is reported in Table VII and the detailed data are contained in appendix B. The most important and surprising result is the rankings of multiples between the pricing errors analysis and the time-series returns analysis are significantly consistent: Forward earnings multiples (including RIMs) performs the best, followed by IACT/P, EBITDA/P and dividend models, placing BV/P third and SALES/P last. However, one interesting finding is that P2, P3 and $\mathrm{P} 4$ perform similar to $\mathrm{P} 1$ or other forward earnings multiples in the time-series returns analysis, contrary to the results in the pricing errors analysis. This indicates RIM delivers similar performance to that of forward earnings multiples in terms of returns generation, but its accuracy varies depending on its terminal value assumptions. Table VII 


\section{Buy-and-Hold Time-Series Returns}

A quintile based buy-and-hold returns are used across up to five years: buying stocks in the top quintile and short-selling stocks in the bottom quintile. Quintiles are generated based on pricing errors for multiples that use the harmonic mean of firms from the same sector.

\begin{tabular}{|c|c|c|c|c|c|c|c|c|c|c|}
\hline \multicolumn{11}{|c|}{ Panel A: Mean of Buy-and-Hold Returns } \\
\hline & \multicolumn{5}{|c|}{ Annual } & \multicolumn{5}{|c|}{ Cumulative } \\
\hline & $T+1$ & $T+2$ & $T+3$ & $T+4$ & $T+5$ & $T+1$ & $T+2$ & $T+3$ & $T+4$ & $T+5$ \\
\hline BV & $26.5 \%$ & $26.0 \%$ & $24.1 \%$ & $21.9 \%$ & $20.5 \%$ & $26.5 \%$ & $55.4 \%$ & $82.0 \%$ & $105.8 \%$ & $130.0 \%$ \\
\hline IACT & $24.9 \%$ & $26.3 \%$ & $23.0 \%$ & $23.6 \%$ & $20.5 \%$ & $24.9 \%$ & $56.1 \%$ & $78.3 \%$ & $115.3 \%$ & $130.9 \%$ \\
\hline EBITDA & $31.5 \%$ & $30.1 \%$ & $25.9 \%$ & $22.8 \%$ & $21.6 \%$ & $31.5 \%$ & $64.8 \%$ & $89.5 \%$ & $111.6 \%$ & $139.5 \%$ \\
\hline SALES & $26.3 \%$ & $26.6 \%$ & $23.4 \%$ & $20.8 \%$ & $18.8 \%$ & $26.3 \%$ & $56.7 \%$ & $79.7 \%$ & $100.1 \%$ & $119.4 \%$ \\
\hline EBITDA/TP & $29.6 \%$ & $29.6 \%$ & $26.1 \%$ & $23.5 \%$ & $22.2 \%$ & $29.6 \%$ & $63.7 \%$ & $89.8 \%$ & $114.9 \%$ & $144.2 \%$ \\
\hline SALES/TP & $25.7 \%$ & $26.1 \%$ & $23.3 \%$ & $20.7 \%$ & $18.9 \%$ & $25.7 \%$ & $55.7 \%$ & $79.2 \%$ & $99.6 \%$ & $120.5 \%$ \\
\hline EPS1 & $25.7 \%$ & $28.0 \%$ & $25.1 \%$ & $23.3 \%$ & $21.6 \%$ & $25.7 \%$ & $59.9 \%$ & $86.3 \%$ & $113.5 \%$ & $138.0 \%$ \\
\hline EPS2 & $24.0 \%$ & $28.8 \%$ & $26.7 \%$ & $23.7 \%$ & $21.9 \%$ & $24.0 \%$ & $61.9 \%$ & $92.1 \%$ & $116.3 \%$ & $141.8 \%$ \\
\hline ES1 & $22.6 \%$ & $27.3 \%$ & $25.1 \%$ & $23.9 \%$ & $22.9 \%$ & $22.6 \%$ & $58.4 \%$ & $85.8 \%$ & $116.8 \%$ & $147.6 \%$ \\
\hline ES2 & $23.4 \%$ & $28.1 \%$ & $25.3 \%$ & $23.2 \%$ & $22.2 \%$ & $23.4 \%$ & $60.2 \%$ & $86.8 \%$ & $113.7 \%$ & $143.3 \%$ \\
\hline$D^{*} / P$ & $24.1 \%$ & $26.7 \%$ & $24.0 \%$ & $21.7 \%$ & $20.9 \%$ & $24.1 \%$ & $57.0 \%$ & $81.7 \%$ & $104.5 \%$ & $132.3 \%$ \\
\hline $\mathrm{P} 1$ & $22.4 \%$ & $27.1 \%$ & $24.9 \%$ & $23.4 \%$ & $22.0 \%$ & $22.4 \%$ & $58.0 \%$ & $85.1 \%$ & $114.8 \%$ & $142.0 \%$ \\
\hline P2 & $25.9 \%$ & $27.5 \%$ & $26.2 \%$ & $24.1 \%$ & $22.6 \%$ & $25.9 \%$ & $58.9 \%$ & $90.1 \%$ & $118.4 \%$ & $145.8 \%$ \\
\hline P3 & $24.9 \%$ & $27.3 \%$ & $25.7 \%$ & $23.7 \%$ & $22.7 \%$ & $24.9 \%$ & $58.5 \%$ & $88.1 \%$ & $115.7 \%$ & $146.8 \%$ \\
\hline P4 & $25.5 \%$ & $27.0 \%$ & $26.3 \%$ & $23.9 \%$ & $22.4 \%$ & $25.5 \%$ & $57.9 \%$ & $90.5 \%$ & $117.2 \%$ & $144.8 \%$ \\
\hline D1 & $22.5 \%$ & $26.0 \%$ & $24.2 \%$ & $22.2 \%$ & $21.1 \%$ & $22.5 \%$ & $55.3 \%$ & $82.6 \%$ & $107.6 \%$ & $134.3 \%$ \\
\hline D2 & $24.0 \%$ & $26.1 \%$ & $24.4 \%$ & $22.8 \%$ & $21.6 \%$ & $24.0 \%$ & $55.7 \%$ & $83.1 \%$ & $110.9 \%$ & $138.2 \%$ \\
\hline D3 & $22.5 \%$ & $25.9 \%$ & $24.2 \%$ & $22.1 \%$ & $21.0 \%$ & $22.5 \%$ & $55.1 \%$ & $82.5 \%$ & $107.1 \%$ & $133.4 \%$ \\
\hline \multicolumn{11}{|c|}{ Panel B: Median of Buy-and-Hold Returns } \\
\hline & \multicolumn{5}{|c|}{ Annual } & \multicolumn{5}{|c|}{ Cumulative } \\
\hline & $T+1$ & $\mathrm{~T}+2$ & $T+3$ & $T+4$ & $T+5$ & $T+1$ & $\mathrm{~T}+2$ & $T+3$ & $T+4$ & $T+5$ \\
\hline BV & $2.0 \%$ & $4.5 \%$ & $5.6 \%$ & $6.8 \%$ & $6.5 \%$ & $2.0 \%$ & $9.6 \%$ & $19.4 \%$ & $32.2 \%$ & $39.9 \%$ \\
\hline IACT & $1.5 \%$ & $3.8 \%$ & $7.0 \%$ & $8.8 \%$ & $5.7 \%$ & $1.5 \%$ & $8.1 \%$ & $24.0 \%$ & $41.4 \%$ & $37.1 \%$ \\
\hline EBITDA & $6.1 \%$ & $6.8 \%$ & $8.7 \%$ & $7.7 \%$ & $6.7 \%$ & $6.1 \%$ & $14.4 \%$ & $29.7 \%$ & $37.2 \%$ & $42.8 \%$ \\
\hline SALES & $1.7 \%$ & $4.1 \%$ & $5.6 \%$ & $5.2 \%$ & $5.6 \%$ & $1.7 \%$ & $8.8 \%$ & $19.8 \%$ & $26.5 \%$ & $36.9 \%$ \\
\hline EBITDA/TP & $5.6 \%$ & $6.8 \%$ & $8.6 \%$ & $8.2 \%$ & $6.7 \%$ & $5.6 \%$ & $14.4 \%$ & $29.2 \%$ & $39.5 \%$ & $42.8 \%$ \\
\hline SALES/TP & $1.0 \%$ & $3.9 \%$ & $5.6 \%$ & $5.1 \%$ & $5.4 \%$ & $1.0 \%$ & $8.4 \%$ & $19.6 \%$ & $25.7 \%$ & $35.7 \%$ \\
\hline EPS1 & $2.2 \%$ & $5.1 \%$ & $7.3 \%$ & $8.2 \%$ & $7.0 \%$ & $2.2 \%$ & $10.7 \%$ & $25.1 \%$ & $38.6 \%$ & $43.1 \%$ \\
\hline EPS2 & $2.3 \%$ & $5.5 \%$ & $8.6 \%$ & $8.7 \%$ & $6.9 \%$ & $2.3 \%$ & $11.6 \%$ & $29.3 \%$ & $41.5 \%$ & $43.1 \%$ \\
\hline ES1 & $1.6 \%$ & $4.4 \%$ & $7.5 \%$ & $8.3 \%$ & $7.9 \%$ & $1.6 \%$ & $9.3 \%$ & $25.0 \%$ & $38.1 \%$ & $47.4 \%$ \\
\hline ES2 & $1.5 \%$ & $4.3 \%$ & $7.4 \%$ & $8.4 \%$ & $7.3 \%$ & $1.5 \%$ & $9.2 \%$ & $25.3 \%$ & $39.7 \%$ & $44.6 \%$ \\
\hline$D^{*} / P$ & $-1.3 \%$ & $2.1 \%$ & $4.0 \%$ & $5.6 \%$ & $4.8 \%$ & $-1.3 \%$ & $4.8 \%$ & $14.3 \%$ & $26.8 \%$ & $30.5 \%$ \\
\hline P1 & $0.8 \%$ & $3.8 \%$ & $7.0 \%$ & $8.5 \%$ & $7.2 \%$ & $0.8 \%$ & $8.2 \%$ & $23.8 \%$ & $40.4 \%$ & $44.3 \%$ \\
\hline P2 & $2.2 \%$ & $4.9 \%$ & $7.1 \%$ & $8.4 \%$ & $7.7 \%$ & $2.2 \%$ & $10.4 \%$ & $24.3 \%$ & $40.4 \%$ & $48.3 \%$ \\
\hline P3 & $2.0 \%$ & $4.3 \%$ & $7.6 \%$ & $8.2 \%$ & $7.1 \%$ & $2.0 \%$ & $9.3 \%$ & $26.1 \%$ & $39.2 \%$ & $44.5 \%$ \\
\hline P4 & $1.6 \%$ & $5.1 \%$ & $7.5 \%$ & $8.0 \%$ & $7.4 \%$ & $1.6 \%$ & $10.9 \%$ & $25.6 \%$ & $38.5 \%$ & $46.7 \%$ \\
\hline D1 & $-1.0 \%$ & $1.4 \%$ & $4.3 \%$ & $6.2 \%$ & $5.8 \%$ & $-1.0 \%$ & $3.3 \%$ & $15.3 \%$ & $29.8 \%$ & $36.0 \%$ \\
\hline D2 & $-0.9 \%$ & $2.4 \%$ & $4.7 \%$ & $7.1 \%$ & $6.1 \%$ & $-0.9 \%$ & $5.3 \%$ & $16.4 \%$ & $33.7 \%$ & $38.0 \%$ \\
\hline D3 & $-1.0 \%$ & $1.1 \%$ & $4.1 \%$ & $6.1 \%$ & $5.7 \%$ & $-1.0 \%$ & $2.6 \%$ & $14.7 \%$ & $29.2 \%$ & $35.9 \%$ \\
\hline
\end{tabular}


Panel A: Annual mean buy-and-hold returns

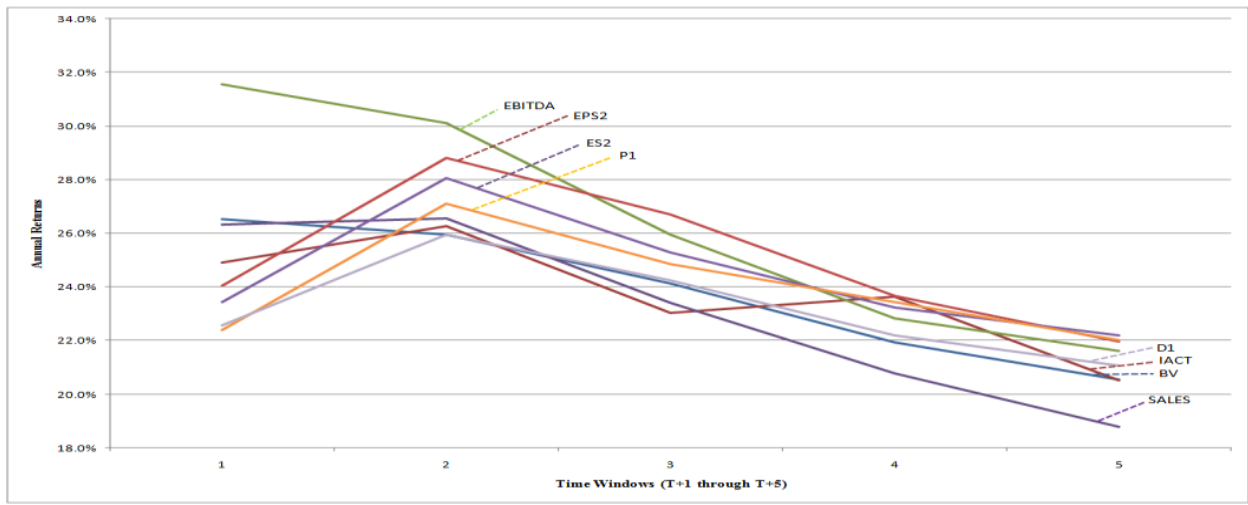

Panel B: Cumulative mean buy-and-hold returns

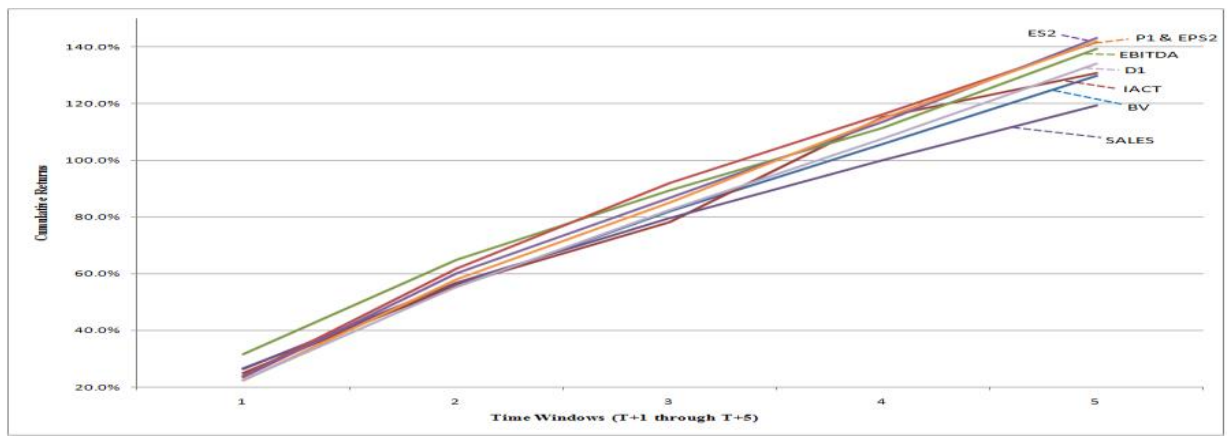

Figure 4. Mean buy-and-hold returns.

Panel A: Annual median buy-and-hold returns

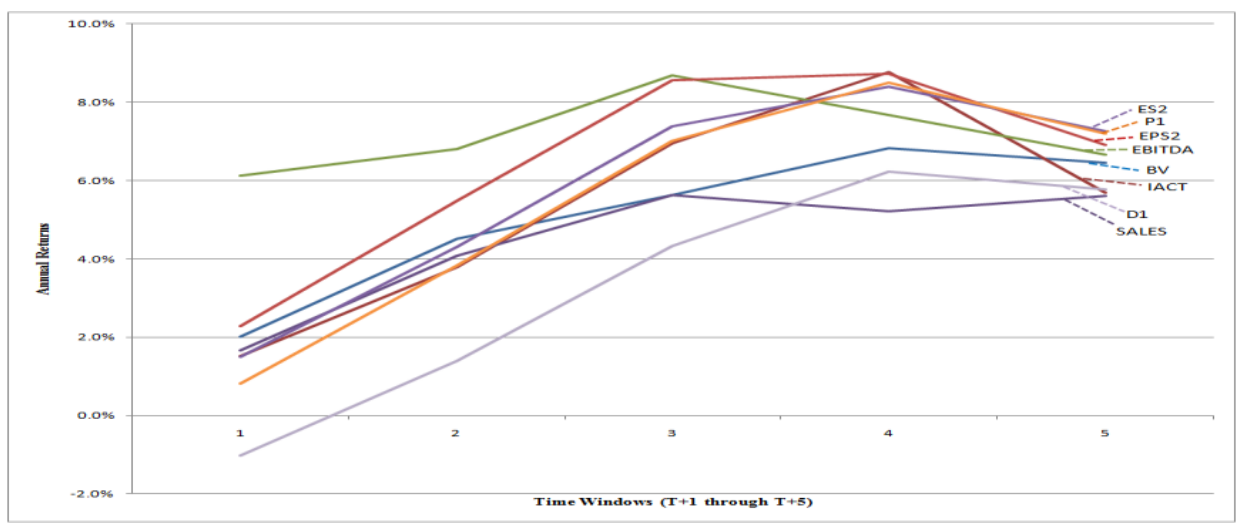

Panel B: Cumulative median buy-and-hold returns 


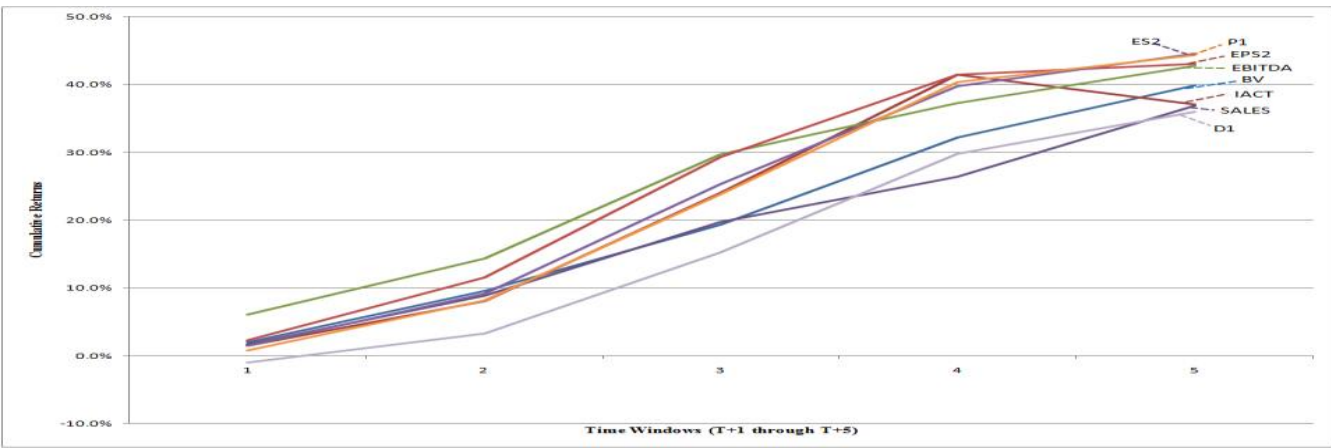

Figure 5. Median buy-and-hold returns.

\section{Conclusions}

The research is motivated by the conflicting preferences for equity valuation models in accounting and finance field. It aims to answer one main question: can the superior models in accounting field be superior in finance field? This means whether the rankings of models in pricing errors terms are consistent with those in time-series returns terms. To match the rankings of models in two different terms, I conduct two different analyses - pricing errors analysis and time-series returns analysis - for various multiples.

The most important finding in this paper is the rankings of multiples in both analyses are significantly consistent: Forward earnings multiples including P1/P performs the best, followed by historical earnings multiples, and DDMs for the third, leaving BV/P and SALES/P at the end. The consistent rankings indicate that the findings in accounting research have practical implications to analysts and investors. One exception is the rankings of the other RIMs (i.e., P2, P3 and P4): they perform considerably worse than P1 in the pricing errors analysis, however, their performances are similar to P1 or other forward earnings multiples in the time-series returns analysis. This implies residual income model produces similar performance to that of forward earnings multiples in terms of returns generation, but its accuracy varies depending on its terminal value assumptions. The main difference between the UK and the US in pricing errors analysis is the rankings of multiples are rather grouped than separated individually, even though overall rankings of individual multiples are consistent. This pattern is observed throughout the research for UK firms. In the sector rankings analysis, I find the consistent rankings that forward earnings multiples including P1 dominate the top four places across sectors. However, the specific rankings between those models within the group change depending on sectors so it is hard to say which one is the best.

In the time-series returns analysis, two interesting findings are observed: (1) short-selling strategy tends to rely on a relatively small number of extreme returns, resulting in positive mean returns between $5 \%$ and $13 \%$ per annum and negative median returns between $-0.6 \%$ and $-6.5 \%$. This indicates more than half of short-selling investments actually generate negative returns so it might be more profitable in general if the strategy is not used; and (2) buy-and-hold returns tend to generate the most reliable annual returns between $T+2$ and $T+4$. This time period is exactly identical with the period that value investment strategy produces its highest annual returns, contrary to momentum strategy that generates its highest returns within one year. This corresponding period is reasonable because buy-and-hold strategy is basically the same as value investment strategy. This paper is unable to answer what are the main factors that improve or deteriorate the performances of residual income models. I leave the answer to this question to future research.

\section{References}

[1] Arnold, John, and Peter Moizer, 1984, A survey of the methods used by UK investment analysts to appraise investments in ordinary shares, Accounting and Business Research 14, 195-207.

[2] Baker, Malcolm, and Richard S. Ruback, 1999, Estimating industry multiples, Working paper, Harvard University.

[3] Barker, Richard G., 1999a, Survey and market-based evidence of industry-dependence in analysts' preferences between the dividend yield and price-earnings ratio valuation models, Journal of Business Finance and Accounting 26, 393-418. 
[4] Barker, Richard G., 1999b, The role of dividends in valuation models used by analysts and fund managers, European Accounting Review 8, 195-218.

[5] Bernard, Victor L., 1995, The Feltham-Ohlson framework: Implications for empiricists, Contemporary Accounting Research 11, 733-747.

[6] Biddle, Gary C., Robert M. Bowen, and James S. Wallace, 1997, Does EVA beat earnings? Evidence on associations with stock returns and firm values, Journal of Accounting and Economics 24, 301-336.

[7] Block, Stanley B., 1999, A study of financial analysts: Practice and theory, Financial Analysts Journal 55, 8695.

[8] Bradshaw, Mark T., 2002, The use of target prices to justify sell-side analysts' stock recommendations, American Accounting Association 16, 27-41.

[9] Brav, Alon, John R. Graham, Campbell R. Harvey, and Roni Michaely, 2005, Payout policy in the 21st century, Journal of Financial Economics 77, 483-527.

[10] Copeland, T., Tim Koller, and Jack Murrin, 2000, Valuation: Measuring and Managing the Value of Companies (John Wiley and Sons, New York).

[11] Courteau, Lucie, Jennifer L. Kao, and Gordon D. Richardson, 2001, Equity valuation employing the ideal versus ad hoc terminal value expressions, Contemporary Accounting Research 18, 625-661.

[12] Demirakos, Efthimios G., Norman C. Strong, and Martin Walker, 2004, What valuation models do analysts use?, Accounting Horizons 18, 221-240.

[13] Dimson, Elroy, Paul Marsh, and Mike Staunton, 2006, The worldwide equity premium: A smaller puzzle, Working paper, London Business School.

[14] Fama, Eugene F., 1970, Efficient capital markets: A review of theory and empirical work, Journal of Finance 25, $383-417$.

[15] Firth, M., 1976, The impact of earnings announcements on the share price behavior of similar type firms, Economic Journal 86, 296-306.

[16] Forker, John, and Ronan Powell, 2008, A comparison of error rates for EVA, residual income, GAAP-earnings and other metrics using a long-window valuation approach, European Accounting Review 17, 471-502.

[17] Frankel, Richard, and Charles M. C. Lee, 1998, Accounting valuation, market expectation, and cross-sectional stock returns, Journal of Accounting and Economics 25, 283-319.

[18] Gode, Dan, and James A. Ohlson, 2006, A unified valuation framework for dividends, free-cash flows, residual income, and earnings growth based models, Working paper, New York University and Arizona State University.

[19] Goedhard, Marc, Timothy Koller, and David Wessels, 2005, The right role for multiples in valuation, McKinsey on Finance 15, 7-11.

[20] Imam, Shahed, Richard Barker, and Colin Clubb, 2008, The use of valuation models by UK investment analysts, European Accounting Review 17, 503-535.

[21] Kaplan, Steven N., and Richard S. Ruback, 1995, The valuation of cash flow forecasts: An empirical analysis, Journal of Finance 50, 1059-1093.

[22] Kim, Moonchul, and Jay R. Ritter, 1999, Valuing IPOs, Journal of Financial Economics 53, 409-437.

[23] Lee, Charles M. C., James Myers, and Bhaskaran Swaminathan, 1999, What is the intrinsic value of the Dow?, Journal of Finance 54, 1693-1741.

[24] Liu, Jing, Doron Nissim, and Jacob Thomas, 2002, Equity valuation using multiples, Journal of Accounting Research 40, 135-172.

[25] Nissim, Doron, and Stephen H. Penman, 2001, Ratio analysis and equity valuation: From research to practice, Review of Accounting Studies 6, 109-154.

[26] Palepu, Krishna G., Paul M. Healy, Victor L. Bernard, and Erik Peek, 2007, Business Analysis and Valuation, IFRS Edition (Cengage Learnings EMEA, London).

[27] Penman, Stephen H., 1996, The articulation of price-earnings ratios and market-to-book ratios and the evaluation of growth, Journal of Accounting Research 34, 235-259.

[28] Penman, Stephen H., 1998, A synthesis of equity valuation techniques and the terminal value calculation for the dividend discount model, Review of Accounting Studies 2, 303-323.

[29] Penman, Stephen H., 2009, Financial Statement Analysis and Security Valuation (McGraw-Hill, Europe). 